\title{
EDITOR'S WORD
}

Starting from this issue, the journal 'Research' substantially adapts its editorial concept to the contemporary scientific criteria and tendencies, determining to publish primarily the research topics which are related to the current Vojvodina region, as well as to the cultural, social and ethnic permeation of nations who have built the national and civilization recognizability within its framework. Ethnic, political, religious and cultural diversities in the context of the meaningful historical existence of the region of the Southeast Europe have provided conditions for the systematic and comprehensive writings on history, which we are willing to pay more attention to. This is also in function of presenting the phase results related to the scientific-research project 'Vojvodina Area in the Context of European History' (no. 177002).

Based on the foundations which have not lost the interest of the scientific public since 1971, when the first volume of the journal 'Research' was published, the journal was restored in 2004, meeting the requirements and norms which defined the journal as a modern and competitive to similar scientific publications abroad, and announced the increase of a number of authors outside the Department of History, at the Faculty of Philosophy in Novi Sad, and the external associates, working on the joint research projects. The previous issues of the 'Research', published from 2004 to 2007, presented an impressive number of scientific papers in the field of archeology and history, highlighting a number of complex issues from political, economic and social history of Serbs and their neighboring nations in this part of Europe. There were also published studies which analyzed the policy of great powers towards nations which were often not counted in large, politically dominant nations. In this point of the editorial approach, we have retained the established direction, trying to maintain continuity necessary for publishing the journals. In the context of the new editorial policies, we have introduced anonymous reviews and other innovations, which will make the journal more modern and popular in the scientific terms.

According to the scientific results based on the latest historiography research, the associates of the 'Research' publish research monographs which are thematically focused precisely on the area that is considered an interesting priority for our editorial policy. 
Having that in mind, as well as based on the experience in the international cooperation, which has been intensified in the previous period, we will try to improve and justify our determination before the scientific public.

In Novi Sad, June 2011

Dr Dejan Mikavica

Editor In Chief 